\title{
Warming Therapy for Spinal Surgery Patients
}

\author{
Keun Young Ham ${ }^{1}$, Hye Young $\mathrm{Ahn}^{2 *}$ and Hye Seon Choi ${ }^{3}$ \\ ${ }^{1}$ Department of Nursing, , Eulji University Hospital \\ ${ }^{2 *}$ College of Nursing, Eulji University \\ 771-77 Beon-gil, Gyeryong-ro, Jung-gu, Daejeon 301-746, South Korea \\ ${ }^{3}$ Department of Nursing, Woosuk University \\ ${ }^{1}$ whiteham4@hanmail.net, ${ }^{2 *}$ ahanaya@eulji.ac.kr, ${ }^{3}$ hschoi@woosuk.ac.kr
}

\begin{abstract}
This study has tested an infrared radiation surgical gown (IRSG) and a carbon nanofiber thermal pad (CNTP) to verify the potential of these new warming therapies for the prevention of hypothermia in spinal surgery patients. The study is a quasiexperimental study using the non-equivalent control group pretest-posttest design. The study period was from July 14 to November 30, 2014, and subjects were an IRSG group of 28 patients, a CNTP group of 30 patients and a control group of 28 patients who were admitted to E university hospital in D city to have spinal surgery. The collected data were analyzed using PASW Statistics 20.0. $\chi^{2}$-test and ANOVA were used to test homogeneity among the three groups, and ANCOVA was used to measure temperature changes and subjective thermal discomfort in order to verify the effectiveness of the experimental treatments. As a result, from 75 minutes after tube insert $(F=8.142, p=.001)$ to the time of its removal $(F=36.825, p<.001)$, esophageal temperatures in the IRSG group and the CNTP group were significantly higher than in the control group. The three groups had significantly high tympanic temperatures with the CNTP group showing the highest temperatures followed by the IRSG and the control group from the time of entering the recovery room $(F=42.820, p<.001)$ to 30 minutes after $(F=51.966, p<.001)$. Also the IRSG group and the CNTP group showed significantly low subjective thermal discomfort at 15 minutes after entering the recovery room $(F=6.737, p=.002)$. The study has confirmed that IRSG and CNTP applied to spinal surgery patients are effective in preventing hypothermia and reducing thermal discomfort during and after surgery. Warming therapy must be provided to patients undergoing spinal surgery under general anesthesia, and hopefully, IRSG and CNTP will be used as an independent nursing intervention.
\end{abstract}

Keywords: Anesthesia, Body Temperature, Hypothermia, Intervention, Surgery

\section{Introduction}

Patients undergoing surgery under general anesthesia have difficulty maintaining their body temperature due to anesthetics. This hinders adequate responses to surgery-related physical and environmental factors [1, 2], causing hypothermia, a drop in body temperature to $35^{\circ} \mathrm{C}$ or lower [3]. Fortunately though, an earlier study has found that the application of warming therapy before surgery is effective in maintaining normal body temperatures during and after surgery [4]. In particular, preoperative warming therapy prevents decreases in core temperature at the early stage of surgery [5, 6], and active warming therapy provided an hour before surgery prevented hypothermia even during and after surgery [5]. Most Korean hospitals, however, use passive warming therapy during and after surgery [7]. Also, it's not easy to provide an active warming intervention that is applied to patients an hour before surgery [4]. 
What is recommended as an effective warming therapy currently is a forced-air warming device. A forced-air warming blanket generates convective currents to circulate warm air and it covers wide areas of body surface. Since warm air delivers heat to the entire body surface, the blanket has lasting warming effects and results in temperature hikes. It has downsides, however. Since the device delivers heat by increasing the temperature of the air, it takes time to deliver the heat to the body surface. In addition, the device is complex to use, costly to purchase and for one-time use only, so it is not costeffective [8-10]. Most importantly, it is not easy to apply this device effectively to spinal surgery patients who have a large part of their body surface exposed since they are put on a special operating table that has holes in its lower part to expose surgical sites. In particular, since spinal surgery needs a prone position, the device is applied only to the scapular areas. This means that spinal surgery patients have difficulty maintaining their normal temperature despite the use of a forced-air warming device because the body surface area to which the device delivers heat is not big enough [11]. Therefore, the development of warming therapies appropriate to spinal surgery patients is required in order to provide nursing intervention that helps them maintain their normal temperature.

Recently, studies are being carried out in various areas to utilize heat efficiently in maintaining body temperature. Some of the leading examples are the study on carbon nanofiber that helps to manage heat efficiently by increasing the contact with the heatgenerating material and the study on Far-Infrared Ray that helps to promote blood circulation to increase body temperature $[12,13]$. However, such new warming therapies are rarely used as practical nursing interventions. This study has applied an infrared radiation surgical gown (IRSG) and a carbon nanofiber thermal pad (CNTP) to verify the potential of the new warming therapies for the prevention of hypothermia.

\section{Methods}

\subsection{Research Design}

The study is a quasi-experimental research study using the non-equivalent control group pretest-posttest design.

\subsection{Subject}

The study period was from July 14 to November 30, 2014, and subjects were an IRSG group of 28 patients, a CNTP group of 30 patients and a control group of 28 patients who were admitted to $\mathrm{E}$ university hospital in D city to have spinal surgery (IRB No. EMC 2014-05-020-001).

The experimental treatments, IRSG and CNTP, were applied to the relevant groups of patients from the time of being transferred to an operating room to the time of returning to a ward. Patients in the IRSG group wore infrared radiation surgical gowns instead of ordinary surgical gowns. For patients in the CNTP group, a carbon nanofiber warming pad was applied to the head and neck, the abdomen, and the upper and lower extremities.

2.2.1. Samples: Patients meeting all of the following criteria were recruited as study subjects.

(1) A patient aged between 10 and 86 undergoing lumbar discectomy, lumbar decompression, lumbar laminectomy or posterior lumbar fusion

(2) A patient included in Class I or II of the American Society of Anesthesiologists (ASA) - Physical Status [14]

(ASA Class I - A normal healthy patient without systemic disturbance.

ASA Class II - A patient with a moderate but definite systemic disturbance, caused either by the condition that is to be treated or surgical intervention or which is caused by 
other existing pathological processes.) A patient with normal vital signs before surgery

(3) A patient who has not received a blood transfusion during surgery

(4) A patient who has not taken medicines affecting body temperature (clonidine, phenothiazine and meperidine)

(5) A patient without endocrine disorder, such as thyroid disease, that affects body temperature regulation

(6) A patient without peripheral vascular disease, such as Raynaud phenomenon and Berger's disease

(7) A patient without medical symptoms needing special attention before surgery other than spinal damage

(8) A patient without problems in taking tympanic temperature

9) A patient who understands the purposes of the study and gives his or her informed consent before taking part in the study.

\subsubsection{Procedure}

\section{1) Experimental Treatment}

The following experimental treatments were applied to experimental group I (the IRSG group), experimental group II (the CNTP group), and the control group.

\section{(1) Experimental Group I (IRSG)}

IRSG Application Period: From the time of being transferred from a ward to an operating room to the time of returning to the ward including the perioperative phases.

(1) To apply the skin warming intervention to as large a body surface area as possible, the subjects wore IRSG (top and bottom).

(2) The IRSG is an infrared radiation-applied surgical gown whose shape and body surface covering are the same as ordinary surgical gowns for spinal surgery patients.

(3) Subjects changed into IRSG before being transferred to an operating room.

(4) Tympanic temperature and subjective thermal discomfort of the subjects were measured right after entering an operating room.

(5) Esophageal temperature of the subjects was taken every 15 minutes from the time of endotracheal tube insert to the time of its removal.

(6) Subjective thermal discomfort was measured right before leaving an operating room after anesthesia ended.

(7) Tympanic temperature and subjective thermal discomfort of the subjects were measured at 5 minute intervals during the 30-minute stay in the recovery room from the time of entering the recovery room to the time of leaving it.

(8) After leaving the recovery room, the subjects continued wearing IRSG up until they returned to their wards.

\section{(2) Experimental Group II (CNTP)}

CNTP Application Period: From the time of being transferred from a ward to an operating room to the time of returning to the ward including the perioperative phases.

(1) To apply the skin warming intervention to as large body surface areas as possible, CNTPs are put on surgery beds and patient transfer trolleys to warm a patient's head and neck, abdomen, and upper and lower extremities.

(2) The CNTP is a specially designed pad whose internal heating wires are not detected by a $\mathrm{C}$-arm during surgery.

(3) To warm the CNTP before applying them to subjects, their temperature was set to $40^{\circ} \mathrm{C}$ for 15 minutes before application. 
(4) Transfer trolleys with CNTP installed were used to transport the subjects to the operating rooms.

(5) Tympanic temperature and subjective thermal discomfort of the subjects were measured right after the entrance into the operating room.

(6) CNTPs were applied on surgery beds from the time of anesthesia induction to the time of end of surgery, and esophageal temperature was taken during the period every 15 minutes.

(7) Subjective thermal discomfort was measured right before leaving the operating room after anesthesia ended.

(8) When subjects were transferred from an operating room to a recovery room, CNTPs were applied to the patient transfer trolleys and during the stay in the recovery room.

(9) Tympanic temperature and subjective thermal discomfort of the subjects were measured at 5 minute intervals during the 30-minute stay in the recovery room from the time of entering the recovery room to the time of leaving it.

(10) Subjects were transferred to their wards on CNTP-applied patient transfer trolleys.

\section{(3) Control Group}

The interventions applied to experimental groups I and II above were not applied to this group.

\subsection{Measurements}

2.3.1. Temperature Changes: Temperatures were taken by inserting an esophageal temperature probe to a mid-esophageal site during surgery, and changes of the temperature were monitored on a monitoring system produced by Hewlett Packard (HP Viridia, M1167A, USA). To monitor temperature changes after surgery, core temperature was taken in the recovery room using a tympanic thermometer (IRT3020, Themoscan, BROUN, Germany).

2.3.2. Subjective Thermal Discomfort: Subjective thermal discomfort was measured using the 0-5 scale VAS (Visual Analogue Scale).

\subsection{Data Analysis:}

The collected data were analyzed using PASW Statistics 20.0. $\chi^{2}$-test and ANOVA were used to test homogeneity among three groups, and ANCOVA was used to measure temperature changes and subjective thermal discomfort in order to verify the effectiveness of the experimental treatments.

\section{Results}

\subsection{Test of Homogeneity between Experimental and Control Groups}

The results of the homogeneity test for general characteristics and surgery-related characteristics of the subjects who underwent spinal surgery under general anesthesia are as shown in (Table 1) and (Table 2).

The homogeneity test for general characteristics (gender, surgery experience, cold discomfort, thyroid disease, anesthesia classification, weight, height, and tympanic temperature taken in a ward) carried out before the experiment showed homogeneity among the three groups with no statistically significant difference found (Table 1). 
Table 1. Homogeneity Test for General Characteristics

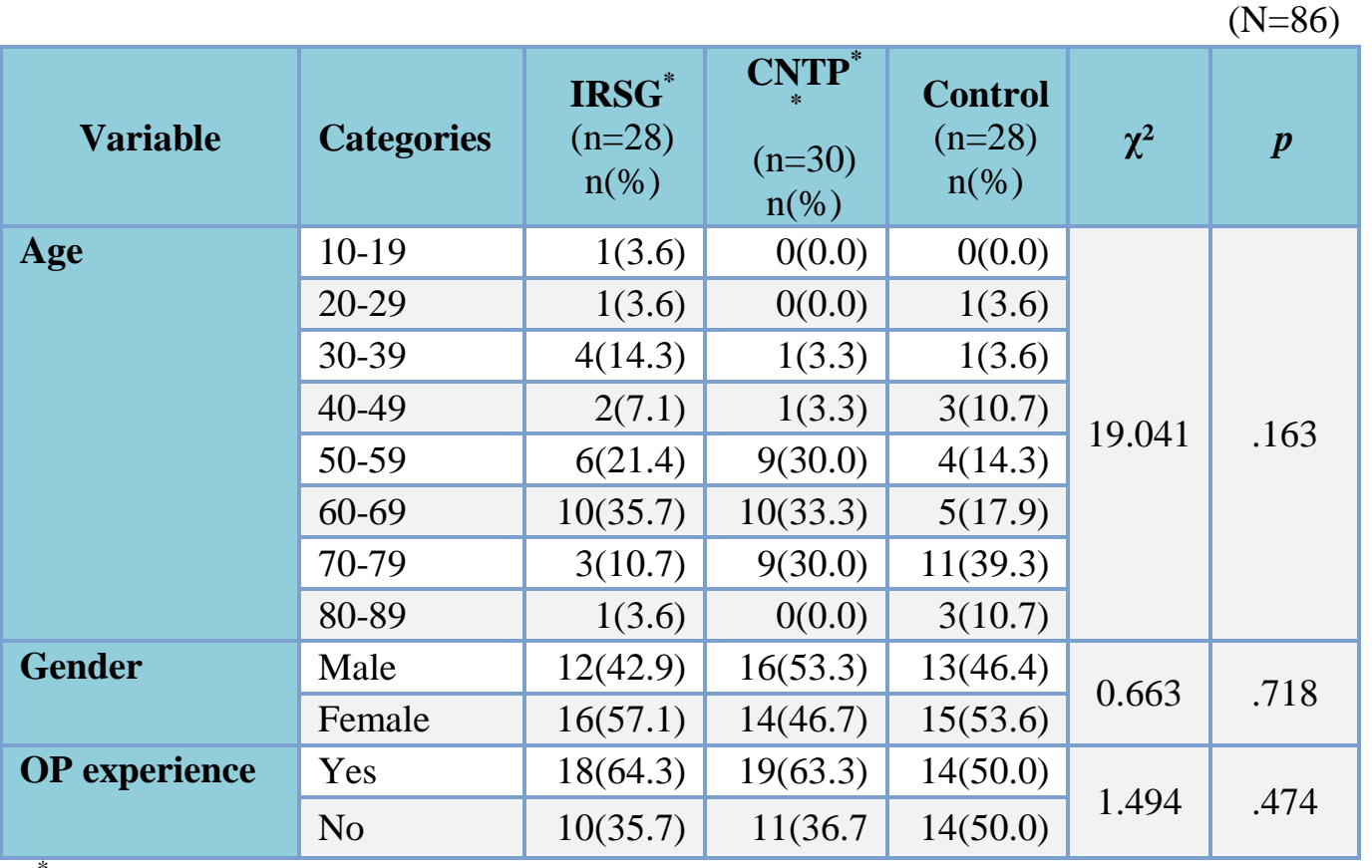

*IRSG : Infrared Radiation Surgical Gown, CNTP : Carbon Nanofiber Thermal Pad

${ }^{* *}$ ASA : American Society of Anesthesiologists - Physical status, OP : Operation

Table 2. Homogeneity Test for Surgery-related Characteristics

\begin{tabular}{|c|c|c|c|c|c|c|}
\hline Variable & Categories & $\begin{array}{c}\text { IRSG }_{(\mathrm{n}=28)} \\
\mathrm{n}(\%)\end{array}$ & $\begin{array}{c}\mathbf{C N T P}^{* *} \\
(\mathrm{n}=30) \\
\mathrm{n}(\%)\end{array}$ & $\begin{array}{c}\text { Contro } \\
\mathbf{l} \\
(\mathrm{n}=28) \\
\mathrm{n}(\%)\end{array}$ & $\chi^{2}$ & $p$ \\
\hline \multirow{3}{*}{$\begin{array}{l}\text { Usual } \\
\text { thermal } \\
\text { discomfort }\end{array}$} & Feel much & $6(21.4)$ & $8(26.7)$ & $6(21.4)$ & \multirow{3}{*}{4.162} & \multirow{3}{*}{.385} \\
\hline & Usually feel & $12(42.9)$ & $15(50.0)$ & $18(64.3)$ & & \\
\hline & No & $10(35.7)$ & $7(23.3)$ & $4(14.3)$ & & \\
\hline \multirow[b]{2}{*}{ Thyroid disease } & Yes & $5(17.9)$ & $1(3.3)$ & $1(3.6)$ & \multirow[b]{2}{*}{5.245} & \multirow[b]{2}{*}{.073} \\
\hline & No & $23(82.1)$ & $29(96.7)$ & $\begin{array}{r}27( \\
96.4)\end{array}$ & & \\
\hline \multirow{2}{*}{ ASA class } & 1 & $3(10.7)$ & $0(0.0)$ & $1(3.6)$ & \multirow{2}{*}{3.858} & \multirow{2}{*}{.145} \\
\hline & 2 & $25(89.3)$ & $30(100.0)$ & $27(96.4)$ & & \\
\hline
\end{tabular}

*IRSG : Infrared Radiation Surgical Gown, CNTP : Carbon Nanofiber Thermal Pad

A*ASA : American Society of Anesthesiologists - Physical status, OP : Operation

The homogeneity test carried out during the experiment for surgery-related characteristics, operating room temperature and humidity, average fluid infusion volume, washout volume, blood loss, total surgery time, the time of point of Bair Hugger application and application period in an operating room, recovery room temperature and humidity, and the time of point of Bair Hugger application and application period in a 
recovery room) showed homogeneity among the three groups with no statistically significant difference found (Table 2).

\subsection{Differences in Esophageal Temperature between Warming Therapies during Surgery}

Table 3 below shows the results of the analysis of differences among three groups in esophageal temperatures taken during surgery from the time of the endotracheal tube insert to the time of its removal.

Table 3. Comparison of Esophageal Temperature during Surgery

\begin{tabular}{|l|c|c|c|c|c|c|}
\hline \multicolumn{1}{|c|}{ Time } & $\begin{array}{c}\text { IRSG } \\
(\mathrm{n}=28) \\
\mathrm{n} / \mathrm{Mean} \pm \text { SD }\end{array}$ & $\begin{array}{c}\text { CNTP } \\
(\mathrm{n}=30) \\
\mathrm{n} \text { Mean } \pm \text { SD }\end{array}$ & $\begin{array}{c}\text { Control } \\
(\mathrm{n}=28) \\
\text { nean } \pm \text { SD }\end{array}$ & F & $p$ & $\begin{array}{c}\text { Bone- } \\
\text { ferroni }\end{array}$ \\
\hline PR & $28 / 36.67 \pm 0.41$ & $30 / 36.61 \pm 0.28$ & $28 / 36.73 \pm 0.29$ & 1.231 & .297 & \\
\hline OR In & $28 / 36.74 \pm 0.35$ & $30 / 36.73 \pm 0.36$ & $28 / 36.70 \pm 0.33$ & 0.055 & .946 & \\
\hline Intubation & $28 / 36.67 \pm 0.32$ & $30 / 36.66 \pm 0.38$ & $28 / 36.63 \pm 0.27$ & 0.073 & .930 & \\
\hline at 15 min & $28 / 36.63 \pm 0.31$ & $30 / 36.58 \pm 0.43$ & $28 / 36.54 \pm 0.34$ & 0.100 & .905 & \\
\hline at 30 min & $28 / 36.50 \pm 0.39$ & $30 / 36.48 \pm 0.52$ & $28 / 36.33 \pm 0.35$ & 0.922 & .402 & \\
\hline at 45 min & $28 / 36.47 \pm 0.40$ & $30 / 36.46 \pm 0.56$ & $28 / 36.24 \pm 0.38$ & 1.705 & .188 & \\
\hline at 60 min & $28 / 36.45 \pm 0.40$ & $30 / 36.47 \pm 0.60$ & $28 / 36.10 \pm 0.40$ & 4.388 & .015 & $\mathrm{~b}>\mathrm{c}$ \\
\hline at 75 min & $28 / 36.44 \pm 0.40$ & $30 / 36.48 \pm 0.59$ & $28 / 36.00 \pm 0.39$ & 8.142 & .001 & a,b>c \\
\hline at 90 min & $28 / 36.43 \pm 0.39$ & $30 / 36.50 \pm 0.59$ & $27 / 35.89 \pm 0.44$ & 12.423 & $<.001$ & a,b>c \\
\hline at 105 min & $27 / 36.43 \pm 0.41$ & $30 / 36.52 \pm 0.56$ & $27 / 35.81 \pm 0.42$ & 17.258 & $<.001$ & a,b>c \\
\hline at 120 min & $24 / 36.43 \pm 0.43$ & $29 / 36.54 \pm 0.54$ & $25 / 35.74 \pm 0.43$ & 19.630 & $<.001$ & a,b>c \\
\hline at 150 min & $21 / 36.44 \pm 0.40$ & $26 / 36.61 \pm 0.47$ & $22 / 35.67 \pm 0.41$ & 28.785 & $<.001$ & a,b>c \\
\hline at 180 min & $14 / 36.51 \pm 0.41$ & $18 / 36.59 \pm 0.42$ & $14 / 35.64 \pm 0.47$ & 23.955 & $<.001$ & a,b>c \\
\hline Extubation & $28 / 36.31 \pm 0.36$ & $30 / 36.58 \pm 0.47$ & $28 / 35.67 \pm 0.44$ & 36.825 & $<.001$ & b>a $>c$ \\
\hline
\end{tabular}

IRSG : Infrared Radiation Surgical Gown, CNTP : Carbon Nanofiber Thermal Pad PR : Patient Room, OR : Operating Room

ANCOVA (covariate: age $=62.21 \mathrm{yr})$

The esophageal temperatures of the subjects in the IRSG group were significantly higher than those of the control group 60 minutes after tube insert $(\mathrm{F}=4.388, \mathrm{p}=.015)$. From 75 minutes after tube insert $(\mathrm{F}=8.142, \mathrm{p}=.001)$ to the time of its removal $(\mathrm{F}=$ $36.825, \mathrm{p}<.001$ ), esophageal temperatures in the IRSG group and the CNTP group were significantly higher than in the control group (Table 3) [15].

This is consistent with the results of an earlier study that compared a carbon heating warming therapy group, a forced-air warming therapy group and a control group during laparoscopic colectomy [16]. According to this earlier study, if patients receive warming therapy for 30 minutes before anesthesia, the body temperature of the carbon heating 
group was higher than those of the forced-air group and the control group by $0.3^{\circ} \mathrm{C}$ and $0.6^{\circ} \mathrm{C}$ each between 40 and 90 minutes after being anesthetized.

\subsection{Differences in Tympanic Temperature between Warming Therapies after Surgery, in the Recovery Room}

Table 4 shows the differences in tympanic temperature between the three groups (IRSG, CNTP and control groups) after surgery in the recovery room.

The three groups had significantly high tympanic temperatures with the CNTP group showing the highest temperatures followed by the IRSG and control groups from the time of entering the recovery room $(\mathrm{F}=42.820, \mathrm{p}<.001)$ to 30 minutes after $(\mathrm{F}=51.966$, $\mathrm{p}<.001$ ) (Table 4) [15].

The higher temperature in the CNTP group in this study supports the results of another earlier study [17]. The study found that the application of a warming garment in which $36.8^{\circ} \mathrm{C}$ water circulates to the patient's upper and lower extremities was effective in maintaining normal body temperature.

Table 4. Comparison of Tympanic Temperature during Stay in Post Anesthetic Room

\begin{tabular}{|l|c|c|c|c|c|c|}
\hline \multicolumn{1}{|c|}{ Time } & $\begin{array}{c}\text { IRSG } \\
(\mathrm{n}=28) \\
\text { Mean } \pm \text { SD }\end{array}$ & $\begin{array}{c}\text { CNTP } \\
(\mathrm{n}=30) \\
\text { Mean } \pm \text { SD }\end{array}$ & $\begin{array}{c}\text { Control } \\
(\mathrm{n}=28) \\
\text { Mean } \pm \text { SD }\end{array}$ & F & $\boldsymbol{p}$ & $\begin{array}{c}\text { Bone- } \\
\text { ferroni }\end{array}$ \\
\hline PAR In & $36.29 \pm 0.27$ & $36.60 \pm 0.41$ & $35.73 \pm 0.44$ & 42.820 & $<.001$ & $\mathrm{~b}>\mathrm{a}>\mathrm{c}$ \\
\hline at 5 min & $36.31 \pm 0.28$ & $36.61 \pm 0.39$ & $35.75 \pm 0.43$ & 44.024 & $<.001$ & $\mathrm{~b}>\mathrm{a}>\mathrm{c}$ \\
\hline at 10 min & $36.34 \pm 0.27$ & $36.63 \pm 0.39$ & $35.80 \pm 0.45$ & 39.884 & $<.001$ & $\mathrm{~b}>\mathrm{a}>\mathrm{c}$ \\
\hline at 15 min & $36.39 \pm 0.25$ & $36.66 \pm 0.35$ & $35.85 \pm 0.45$ & 40.926 & $<.001$ & $\mathrm{~b}>\mathrm{a}>\mathrm{c}$ \\
\hline at 20 min & $36.40 \pm 0.22$ & $36.67 \pm 0.34$ & $35.87 \pm 0.45$ & 42.847 & $<.001$ & $\mathrm{~b}>\mathrm{a}>\mathrm{c}$ \\
\hline at 25 min & $36.42 \pm 0.22$ & $36.69 \pm 0.32$ & $35.93 \pm 0.45$ & 39.245 & $<.001$ & $\mathrm{~b}>\mathrm{a}>\mathrm{c}$ \\
\hline at 30 min & $36.46 \pm 0.21$ & $36.73 \pm 0.29$ & $35.91 \pm 0.43$ & 51.966 & $<.001$ & $\mathrm{~b}>\mathrm{a}>\mathrm{c}$ \\
\hline
\end{tabular}

IRSG : Infrared Radiation Surgical Gown, CNTP : Carbon Nanofiber Thermal Pad

PAR : Post Anesthesia Room

ANCOVA (covariate: age $=62.21 \mathrm{yr}$ )

\subsection{Differences in Subjective Thermal Discomfort between Warm Therapies in a Recovery room after Surgery.}

Differences in subjective thermal discomfort between the three groups (IRSG, CNTP and control group) in the recovery room after surgery are as shown below in Table 5 .

Compared to the control group, the subjective thermal discomfort of the IRSG group was significantly low 10 minutes after the entrance into the recovery room $(\mathrm{F}=7.514, \mathrm{p}$ $=.001$ ) and the IRSG group and the CNTP group showed significantly low subjective thermal discomfort 15 minutes after the entrance into the recovery room $(F=6.737, p$ $=.002)($ Table5).

These results were the same as the results of an earlier study [4] that revealed continuous warm therapy before and after surgery promotes body relaxation, lowering subjective thermal discomfort. Overall, however, the results of this study were partially consistent with the earlier study as there is no significant difference between the three 
groups from 20 minutes after the entrance into the recovery room to the time of ending the measurement. The reasons for this result seem to be the pain occurring during the recovery of consciousness and the temporary application of the forced-air warming device to patients in the control group whose body temperature went down to $36^{\circ} \mathrm{C}$ or lower, to prevent complications.

Table 5. Comparison of Subjective Thermal Discomfort in Post Anesthetic Room

\begin{tabular}{|l|c|c|c|c|c|c|}
\hline \multicolumn{1}{|c|}{ Time } & $\begin{array}{c}\text { IRSG } \\
(\mathrm{n}=28) \\
\text { Mean } \pm \text { SD }\end{array}$ & $\begin{array}{c}\text { CNTP } \\
(\mathrm{n}=30) \\
\text { Mean } \pm \text { SD }\end{array}$ & $\begin{array}{c}\text { Control } \\
(\mathrm{n}=28) \\
\text { Mean } \pm \text { SD }\end{array}$ & $\mathbf{F}$ & $\boldsymbol{p}$ & $\begin{array}{c}\text { Bone- } \\
\text { ferroni }\end{array}$ \\
\hline PAR In & $1.21 \pm 0.63$ & $1.07 \pm 0.25$ & $1.46 \pm 0.96$ & 2.531 & .086 & \\
\hline at 5 min & $1.14 \pm 0.45$ & $1.07 \pm 0.25$ & $1.29 \pm 0.54$ & 1.862 & .162 & \\
\hline at10min & $1.18 \pm 0.48$ & $1.00 \pm 0.00$ & $1.46 \pm 0.64$ & 7.514 & .001 & $\mathrm{c}>\mathrm{b}$ \\
\hline at 15 min & $1.11 \pm 0.32$ & $1.03 \pm 0.18$ & $1.43 \pm 0.63$ & 6.737 & .002 & $\mathrm{c}>\mathrm{a}, \mathrm{b}$ \\
\hline at $20 \mathrm{~min}$ & $1.18 \pm 0.39$ & $1.00 \pm 0.00$ & $1.21 \pm 0.50$ & 2.908 & .060 & \\
\hline at 25 min & $1.07 \pm 0.26$ & $1.00 \pm 0.00$ & $1.14 \pm 0.45$ & 1.712 & .187 & \\
\hline at 30 min & $1.04 \pm 0.19$ & $1.03 \pm 0.18$ & $1.04 \pm 0.19$ & 0.047 & .955 & \\
\hline
\end{tabular}

IRSG : Infrared Radiation Surgical Gown, CNTP : Carbon Nanofiber Thermal Pad

PAR : Post Anesthesia Room

ANCOVA (covariate: age $=62.21 \mathrm{yr}$ )

3.5. Difference between the Experimental Groups and the Control Group in the Application of the Forced-air warming during and after the Surgery

The difference between the experimental groups (the IRSG group and the CNTP group) and the control group in the application of the forced-air warming during and after surgery are as shown below in Table 6 .

The hypothesis that "there will be a difference between the experimental groups (the IRSG group and the CNTP group) and the control group in the application of the forced-air warming during and after surgery" was partially supported since meaningful difference in the application of the forced-air warming was found after the surgery $(\mathrm{F}=22.344, \mathrm{p}<.001)$.

Table 6. Applies Whether or Not of Bair Hugger during Stay in Surgery and Post Anesthetic Room

\begin{tabular}{|c|c|c|c|c|c|c|}
\hline Variable & Categories & $\begin{array}{c}\text { IRSG } \\
(\mathrm{n}=28) \\
\mathbf{n}(\%)\end{array}$ & $\begin{array}{c}\text { CNTP } \\
(\mathrm{n}=30) \\
\mathbf{n}(\%)\end{array}$ & $\begin{array}{c}\text { Control } \\
(n=28) \\
n(\%)\end{array}$ & $\chi^{2}$ & $p$ \\
\hline \multirow{2}{*}{$\begin{array}{l}\text { OR } \\
\text { Bair } \\
\text { Hugger }\end{array}$} & Yes & $7(25.0)$ & $6(20.0)$ & $13(46.4)$ & \multirow{2}{*}{5.335} & \multirow{2}{*}{.069} \\
\hline & No & $21(75.0)$ & $24(80.0)$ & $15(53.6)$ & & \\
\hline PAR & Yes & $1(3.6)$ & $0(0.0)$ & 11(39.3) & 22.344 & $<.001$ \\
\hline
\end{tabular}




\begin{tabular}{|l|l|l|l|l|l|l|}
\cline { 2 - 6 } $\begin{array}{l}\text { Bair } \\
\text { Hugger }\end{array}$ & No & $27(96.4)$ & $30(100.0)$ & $17(60.7)$ & & \\
\hline
\end{tabular}

IRSG : Infrared Radiation Surgical Gown, CNTP : Carbon Nanofiber Thermal Pad OP : Operation, PAR : Post Anesthesia Room

\section{Conclusion}

Spinal surgery uses a specially designed operating bed that has holes in its lower section to expose the surgical site of a patient lying in a prone position. Therefore, it is difficult to apply warming therapy on this operating bed to the patient's maximum body surface areas. In addition, the forced-air warming device, which is known to be the most effective warm therapy, can only be applied to the scapular areas [11]. This makes it difficult for patients to maintain normal body temperature since the area where heat is delivered is very limited. Warming therapy to prevent hypothermia is a prerequisite since spinal surgery lasts more than 2 to 3 hours [18]. Against this background, this study analyzed the effects of IRSG and CNTP on body temperature changes during and after surgery and subjective thermal discomfort in the recovery room by applying them to patients undergoing spinal surgery in a prone position under general anesthesia from the time of being transferred to an operating room to the time of returning to a recovery room.

The study has confirmed that IRSG and CNTP applied to spinal surgery patients are effective in preventing hypothermia and reducing thermal discomfort during and after surgery. Generally, patients experience a drastic drop in body temperature by $1-1.5^{\circ} \mathrm{C}$ for an hour after being put under general anesthesia. But, the drop was about $0.3^{\circ} \mathrm{C}$ in this study. What is particularly notable is that the patients in the CNTP group showed the highest body temperatures from 60 minutes after tracheal tube insertion to the time of leaving the recovery room. On the contrary, those in the control group left the recovery room with about a $1^{\circ} \mathrm{C}$ drop in body temperature or with hypothermia. All this testifies that IRSG and CNTP warming therapies that can deliver heat to large parts of body surface areas are also effective in maintaining normal body temperatures, preventing hypothermia and increasing body temperature during and after surgery. Warming therapy must be provided to patients undergoing spinal surgery under general anesthesia, and hopefully, IRSG and CNTP will be used as independent nursing interventions [15].

\section{References}

[1] S. Y. Kim, “Anesthesiology \& Pain Medicine”, Ryomoongak, Seoul (2010).

[2] K. O. Lee and Y. J. Son, "Factors Influencing Length of Stay among Patients with General Anesthesia at the Recovery Room", Clinical Nursing Research, vol. 12, no. 2, (2006), pp. 133-143.

[3] F. Hildebrand, P. V. Giannoudis, M. Griensven, M. Chawda and H. C. Pape, "Pathophysiologic Changes and Effects of Hypothermia on Outcome in Elective Surgery and Trauma Patients", The American Journal of Surgery, vol. 187, no. 3, (2004), pp. 363-371.

[4] J. O. Kim, Y. Chung and Y. J. Park, "The Effects of Warming Methods on Anxiety and Cold Discomfort of Patients Undergoing Operation under Spinal Anesthesia”, The Medical Journal of Chosun University, vol. 33, no. 2, (2008), pp. 96-109.

[5] J. Andrzejowski, J. Hoyle, G. Eapen and D. Turnbull, "Effect of Prewarming on Post-induction Core Temperature and the Incidence of Inadvertent Perioperative Hypothermia in Patients Undergoing General Anaesthesia", British Journal of Anaesthesia, vol. 101, no. 5, (2008), pp. 627-631.

[6] P. Kiekkas and M. Karga, "Prewarming: Preventing Intraoperative Hypothermia", British Journal of Perioperative Nursing, vol. 15 , no. 10, (2005), pp. 444-451.

[7] J. B. Yoo, H. J. Park, J. Y. Chae, E. J. Lee, Y. J. Shin, J. S. Ko and N. C. Kim, "Effects of ASPAN's Evidence-based Clinical Practice Guidelines for Promotion of Hypothermia of Patients with Total Knee Replacement Arthroplasty", Journal of Korean Academy Nursing. vol. 43, no. 3, (2013), pp. 352-360.

[8] C. Negishi, K. Hasegawa, S. Mukai, F. Nakagawa, M. Ozaki and D. I. Sessler, "Resistive-heating and Forced-air Warming are Comparably Effective", Anesthesia \& Analgesia, vol. 96, no. 6, (2003), pp. 1683-1687.

[9] K. H. Choi, "Comparison of Forced Air Warming and Radiant Heating on Body Temperature and Shivering of Post-operative Patients", Journal of Korean Academy of Adult Nursing, vol. 20, no. 1, (2008), pp. 135-148. 
[10] S. O. Lee, "The Effects of Warming Interventions on Body Temperature and Thermal Discomfort in LAVH Patients", Master's thesis, Eulji University, Daejeon, (2008).

[11] H. J. Kim, G. E. Jeon, J. M. Choi, S. M. Jeong, K. W. Seong and H. S. Yang, "The Effects of Temperature Monitoring Methods and Thermal Management Methods During Spinal Surgery", Korean Journal of Anesthesiology, vol. 54, no. 6, (2008), pp. 623-628.

[12] J. N. Kim, W. J. Na and W. R. Yu, "Fabrication of Networked Carbon Nanofiber Mats, and Analysis of Their Thermal Properties", Textile Science and Engineering, vol. 50, no. 4, (2013), pp. 232-240.

[13] S. M. Schieke, P. Schroeder and J. Krutmann, "Cutaneous Effects of Infrared Radiation: from Clinical Observations to Molecular Response Mechanisms", Photodermatology, Photoimmunology \& Photomedicine, vol. 19, no. 5, (2003), pp. 228-234.

[14] American Society of Anesthesiologists, https://www.asahq.org/resources/clinical-information/asaphysical-status-classification-system, (2014).

[15] K. Y. Ham, H. Y. Ahn and H. S. Choi, "Effects of Warming Therapy on Body Temperature in Spinal Surgery Patients", Proceedings of the 9th International Conference of SERSC (Healthcare and Nursing), Jeju, Korea, (2016).

[16] J. L. DeWitte, C. Demeyer and E. Vandemaele, "Resistive-heating or Forced-air Warming for the Prevention of Redistribution Hypothermia", Anesthesia \& Analgesia, vol. 110, no. 3, (2010), pp. 829833.

[17] P. K. Janicki, M. S. Higgins, J. Janssen, R. F. Johnson and C. Beattie, "Comparison of Two Different Temperature Maintenance Strategies during Open Abdominal Surgery: Upper Body Forced-air Warming versus Whole Body Water Garment”, Anesthesiology, vol. 95, no. 4, (2001), pp. 868-874.

[18] J. Y. Lee, "Comparison of the Effects of Warming Therapy on Spine Surgery Patients According to Its Applied Parts", Master's thesis, Sungkyunkwan University, Seoul, (2014).

\section{Authors}

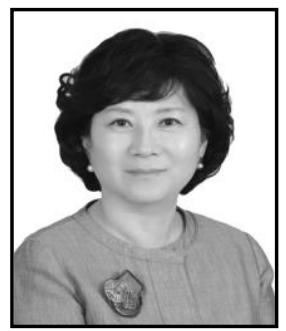

Keun Young Ham, she is has a degree of Master of Science in Nursing, Eulji University, Daejeon, Korea. E-mail: whiteham47@hanmail.net

Hye Young Ahn, received her Bachelor of Science in Nursing at Seoul National University, Seoul, Korea. She has a Master of Science in Nursing degree at Seoul National University, Seoul, Korea. She is a Doctor of Science in Nursing, Seoul National University, Seoul, Korea. She is a professor at the Department of Nursing, Eulji University, Daejeon, Korea. E-mail: ahanaya@eulji.ac.kr 